\title{
0 vírus da língua azul em ruminantes domésticos: situação de alerta no Brasil - Revisão
}

\author{
Bluetongue virus in domestic ruminants: state of alert in Brazil - Review
}

Ariane Paula Rovani Scolari[ ${ }^{[a]}$,Bruna Rayet Ayub ${ }^{[b]}$, Cristina Santos Sotomaior ${ }^{[c]}$, Rüdiger Daniel Ollhoff[d]

[a] Médica-Veterinária, especialista, mestre em Ciência Animal, Pontifícia Universidade Católica do Paraná (PUCPR), Curitiba, PR - Brasil, e-mail: scolariapr@gmail.com

[b] Médica-Veterinária, professora do curso de Medicina Veterinária das Faculdades Integradas do Vale do Iguaçu (UNIGUAÇU), União da Vitória, PR - Brasil, e-mail: bruna.a@veterinaria.med.br

[c] Médica-Veterinária, doutora, professora do mestrado em Ciência Animal, Pontifícia Universidade Católica do Paraná (PUCPR), Curitiba, PR - Brasil, e-mail: cssoto@onda.com.br

[d] Médico-Veterinário, doutor, professor do mestrado em Ciência Animal, Pontifícia Universidade Católica do Paraná (PUCPR), Curitiba, PR - Brasil, e-mail: ollhoff@gmail.com

\section{Resumo}

A língua azul (LA) é uma doença viral não contagiosa de ruminantes, transmitida por artrópodes. 0 vírus da língua azul (VLA) pode causar doença severa em ovinos, mas raramente em bovinos, caprinos e na maioria dos ruminantes selvagens. De distribuição cosmopolita, a moléstia foi descrita pela primeira vez no Brasil em bovinos e ovinos no Estado de São Paulo. Posteriormente, foram relatados casos de doença clínica no Paraná e, recentemente, no Rio Grande do Sul. A presença sorológica do vírus foi detectada em MG, RJ, PA, SP, CE, MS, PE, BA e RS. No Paraná, o primeiro caso clínico foi identificado em 2002, em caprino, e desde então, nenhuma pesquisa foi realizada para investigar a circulação viral na região. A taxa de mortalidade e a severidade dos sinais clínicos são influenciadas por espécie, raça, idade, status imunológico, sorotipo e amostra do VLA do animal infectado, e por interações com o meio ambiente. Não existem vacinas disponíveis contra o VLA no mercado brasileiro e, apesar da presença do vírus em 12 Estados da Federação, nenhum programa de prevenção foi implementado. 0 estudo tem como objetivo realizar uma revisão sobre a situação do VLA no Brasil, bem como advertir os órgãos competentes sobre os prejuízos que essa doença provoca.

Palavras-chave: Doenças virais. Ruminantes domésticos. Brasil.

\section{Abstract}

Bluetongue (BT) is an arthropod-borne, non-contagious and economically important viral disease of ruminants with worldwide distribution. Bluetongue virus (BTV) can cause severe illness in some breeds of sheep and deer, but rarely causes disease in cattle, goats and most of wild ruminants. In Brazil, BT was firstly recorded in 1978 from 
cattle and sheep raised in the State of São Paulo. Since then, viral circulation has been demonstrated in the States of Rio Grande do Sul, Minas Gerais, Paraiba, Mato Grosso do Sul and Parana. The latter had its first clinical case identified ten years ago in goats. Mortality rate and severity of clinical signs depends on the specie affected, breed, age, immunological status of the animal, serotype of BTV and also interactions with the environment. Although BTV is present in 12 States of Brazil, there are no vaccines available against this virus in the Brazilian market and no prevention program has been implemented yet. The present study intends to review the alarming situation of BTV in Brazil and warn the competent bodies about the losses that this disease causes.

Keywords: Viral diseases. Domestic ruminants. Brazil.

\section{Introdução}

A língua azul (LA) é uma enfermidade infecciosa, viral, transmissível e não contagiosa, que acomete ruminantes selvagens e domésticos, como ovinos, caprinos, bovinos, bubalinos, cervídeos e outros artiodátilos (Office International des Epizooties - OIE, 2008).

0 vírus da língua azul (VLA) está presente em diversos países que se estendem entre as latitudes $40^{\circ}$ $50^{\circ} \mathrm{N}$ e $35^{\circ} \mathrm{S}$ do globo terrestre, sendo encontrado principalmente em regiões detentoras de condições favoráveis para a presença do seu vetor, o Culicoides (África, Américas e alguns países da Ásia e Oceania) (GIBBS; GREINER, 1994). Os primeiros trabalhos objetivando a identificação de dípteros Culicoides (Diptera: Ceratopogonidade) no Brasil foram realizados na década de 60 (GOMES, 1987). No país, esses mosquitos são denominados como "maruim", "mosquito pólvora”, "mosquito do mangue" ou "borrachudo" (PINHEIRO et al., 2003). Em ovinos no Rio Grande do Sul, o Culicoides insignis foi considerado o causador de uma dermatite alérgica sazonal descrita por Corrêa et al. (2007).

Segundo MacLachlan (2004), a maioria das infecções nos ovinos produz alterações pouco evidentes ou brandas, ocorrendo surtos clínicos somente quando ovinos suscetíveis são introduzidos em áreas endêmicas ou quando o vírus se propaga em populações sem prévio contato em regiões limítrofes entre áreas endêmicas e não endêmicas. Segundo Tomich (2007), a incidência da doença clínica é altamente variável. Alterações na concentração, motilidade e quantidade de espermatozoides vivos em sêmen ovino (KIRCHVINK et al., 2009) e motilidade em sêmen bovino (MÜLLER et al., 2010) foram observados em animais infectados.

Estudos da OIE (2008) apontam que a morbidade em ovinos pode chegar a $100 \%$, com mortalidade entre $0 \%$ e $30 \%$, podendo chegar a $70 \%$, dependendo da raça, sorotipo e estresses dos animais oriundos do meio ambiente. Nos bovinos, até $5 \%$ dos animais podem se tornar doentes; contudo, apresentam taxa de mortalidade abaixo de 1\%. A taxa de mortalidade e a severidade dos sinais clínicos são influenciadas por espécie, raça, idade, status imunológico, sorotipo, amostra do VLA e por interações dos animais com o meio ambiente (TOMICH, 2007). De acordo com o Código Sanitário de Animais Terrestres da Organização Mundial de Saúde Animal (OIE, 2008), a LA é de notificação obrigatória.

Walton et al. (1984) citam que, além das perdas econômicas com a doença em si, a LA é usada como argumento para restringir a livre circulação internacional de animais, do germoplasma e dos produtos de origem deles. Portanto, as consequências socioeconômicas são graves, uma vez que a LA foi incluída entre as seis doenças com o maior risco sanitário para os rebanhos europeus dentro de um cenário de aumento no comércio internacional de animais e seus subprodutos e o aquecimento global (DUFOUR et al., 2008). Na Holanda, em 2006, a doença da LA causou perdas de 32,4 milhões de euros, principalmente em função das restrições no comércio internacional (VELTHUIS et al., 2010). A Imunodifusão em Gel de Ágar (IDGA) e o teste de ELISA têm sido usados na vigilância epidemiológica para a emissão de certificados para o comércio internacional de animais e de seus produtos, segundo o Manual Padrão para Testes de Diagnóstico e Vacinas para Animais Terrestres (MERCOSUL/GMC/ RES, 2005; OIE, 2008).

O objetivo da revisão foi avaliar a abrangência da disseminação do VLA no território brasileiro, assim como demonstrar os sorotipos encontrados e os potenciais riscos decorrentes da presença do vírus nos rebanhos de bovinos, caprinos e ovinos. 


\section{Literatura}

O VLA possui 24 sorotipos identificados, denominados de BTV-1 a BTV-24 (SCHWARTZ-CORNIL et al., 2008). Os 24 sorotipos diferentes podem apresentar reações cruzadas entre si, sendo possível diferenciá-los por técnicas de soroneutralização ou por reações específicas de suas proteínas (VENDITTI, 2009). No Brasil, foram isolados os sorotipos 4 e 12; o sorotipo 4 foi descrito por Groocock e Campbell (1982) em bovinos importados do Brasil para os Estados Unidos, e o sorotipo 12, em um caprino do Estado do Paraná, isolado por Clavijo et al. (2002). Segundo Clavijo et al. (2002), o primeiro isolamento viral no Brasil data de 1980, do sorotipo 4, em bovinos que foram exportados para os Estados Unidos, sendo que 13,3\% produziram anticorpos contra o VLA durante o período de quarentena no país de destino e foram sacrificados. Já em abril de 2001, em um município da Região Metropolitana de Curitiba (Paraná), os autores isolaram o sorotipo 12 do VLA, ao inocularem sangue de animais sintomáticos em ovos embrionados durante um surto ocorrido, sendo que 21 ovelhas e um caprino demonstraram sinais clínicos da doença. No surto, dois ovinos e um caprino vieram a óbito pela doença; outros 128 ovinos e dois caprinos remanescentes foram sacrificados. Essa foi a primeira confirmação por meio de isolamento viral da manifestação clínica no Brasil e na América do Sul (CLAVIJO et al., 2002). Novas pesquisas brasileiras são necessárias para o reconhecimento de outros sorotipos e o estabelecimento de associações entre sinais clínicos, patogenias e formas de prevenção.

Diversos estudos sorológicos em diferentes regiões do Brasil demonstram que o VLA encontra-se distribuído em todo o território brasileiro. Uma compilação de autores brasileiros a respeito da presença do VLA nos animais pela sorologia é mostrada no Quadro 1. Observa-se que a soroprevalência na espécie bovina variou de $0,6 \%$ a $76 \%$, de $6 \%$ a $44 \%$ na caprina, ocorrendo na espécie ovina a maior variabilidade de animais soropositivos.

Recentemente, Antoniassi (2010) encontrou ovinos clinicamente doentes com o sorotipo 12 no Rio Grande do Sul.

Uma vez detectada, a LA gera consequências socioeconômicas ou sanitárias graves, com severa repercussão no comércio internacional de animais e produtos de origem animal, pois, uma vez introduzida em um determinado país, a possibilidade de sua erradicação é pequena (KONRAD et al., 2003).

Segundo Tomich et al. (2009), as principais consequências econômicas da infecção pelo VLA são perdas indiretas em virtude do aborto, queda do desempenho reprodutivo, redução da produção de leite e perda de condição corporal, além da restrição internacional de movimentação animal.

Saegerman et al. (2010) estudaram 476 ovinos e 26 fetos abortados por 300 ovelhas durante sete meses, concluindo que a infecção transplacentária ocorre em animais naturalmente infectados pelo VLA de sorotipo 8. 0 desempenho reprodutivo desse rebanho diminuiu consideravelmente, pois $25 \%$ das ovelhas abortaram e a taxa de fertilidade caiu para 50\%.

As restrições impostas por países importadores de produtos derivados de bovinos e ovinos, em função da imposição de testes para a exportação de animais e sêmen, bem como as próprias perdas diretas nos rebanhos afetados, causam um grande impacto econômico no Brasil, porém não são encontrados dados numéricos financeiros a esse respeito na literatura.

A movimentação do rebanho entre países vizinhos do Mercosul (Brasil, Argentina, Paraguai e Uruguai) exige uma análise obrigatória da presença do VLA ou de anticorpos (sorologia) nos animais ou em seus produtos (MERCOSUL/GMC/RES, 2005).

Segundo Alves et al. (2008), as perdas econômicas causadas pela LA estão ligadas às restrições na importação e exportação de animais e de seu material genético e aos transtornos reprodutivos associados a essa doença. Além desses, o fato de o bovino tomar o papel de reservatório, aliado ao cuidado dos outros países com focos de infecção e contaminação biológica dos produtos, dificultam o comércio no Mercosul, nos Estados Unidos e na Europa.

O Brasil possui enorme potencial de produção e exportação de carnes, sêmen e embriões. Contudo, diante da proliferação de barreiras sanitárias no comércio internacional, existe a necessidade de reforçar a confiança com os importadores a fim de garantir a segurança das relações comerciais. Como pode ser observado no Quadro 1, a infecção pelo VLA está disseminada pelo território nacional do extremo sul até o Amazonas. No entanto, todos os dados disponíveis na literatura científica advêm de iniciativas individuais de pesquisadores da área, inexistindo a 
SCOLARI, A. P. R. et al.

Quadro 1 - Prevalência do VLA no Brasil em diferentes espécies de ruminantes soropositivos ordenadas cronologicamente

\begin{tabular}{|c|c|c|c|}
\hline Autor & Estado & Espécie & Positivos \\
\hline Moreira et al.(1980) & Minas Gerais & Bovina & $74 \%$ \\
\hline Cunha et al.(1982) & Rio de Janeiro & Bovina & $41 \%$ \\
\hline Abreu (1982) & Roraima & Bovina & $16 \%$ \\
\hline Abreu (1982) & Amazonas & Bovina & $26 \%$ \\
\hline Abreu (1982) & Pará & Bovina & $33 \%$ \\
\hline Abreu (1982) & Pará & Bovina & $21 \%$ \\
\hline Cunha et al. (1987) & Paraná & Bovina & $20 \%$ \\
\hline Cunha et al.(1987) & São Paulo & Bovina & $54 \%$ \\
\hline Cunha et al.(1987) & Santa Catarina & Bovina & $37 \%$ \\
\hline Cunha et al.(1987) & Rio Grande do Sul & Bovina & $1 \%$ \\
\hline Cunha et al.(1988) & Rio de Janeiro & Caprina & $44 \%$ \\
\hline Cunha et al. (1988) & Rio de Janeiro & Ovina & $24 \%$ \\
\hline Silva et al.(1988) & Minas Gerais & Caprina & $6 \%$ \\
\hline Arita et al.(1992) & São Paulo & Ovina & $53 \%$ \\
\hline Castro et al.(1992) & Minas Gerais & Bovina & $76 \%$ \\
\hline Lobato et al.(2001) & Minas Gerais & Ovina & $65 \%$ \\
\hline Lobato et al.(2001) & Minas Gerais & Caprina & $42 \%$ \\
\hline Costa (2000) & Rio Grande do Sul & Ovina & $0,1 \%$ \\
\hline Costa (2000) & Rio Grande do Sul & Bovina & $0,6 \%$ \\
\hline Frota et al.(2001) & Ceará & Ovinos & $13,6 \%$ \\
\hline Silva (2002) & Ceará & Caprina & $31 \%$ \\
\hline Konrad et al.(2003) & Minas Gerais & Bovinos & $59,5 \%$ \\
\hline Costa et al. (2006) & Rio Grande do Sul & Ovinos & $0,1 \%$ \\
\hline Costa et al. (2006) & Rio Grande do Sul & Bovinos & $0,6 \%$ \\
\hline Alves et al. (2008) & Paraíba & Ovina & $4,1 \%$ \\
\hline Nogueira (2009) & São Paulo & Ovina & $65 \%$ \\
\hline Motta (2009) & Pernambuco & Ovinos & $27,5 \%$ \\
\hline Motta (2009) & Pernambuco & Caprinos & $24,3 \%$ \\
\hline Tomich et al.(2009) & Mato Grosso do Sul & Ovina & $10,9 \%$ \\
\hline Tomich et al.(2009) & Mato Grosso do Sul & Bovina & $42 \%$ \\
\hline Tomich et al.(2009) & Mato Grosso do Sul & Veados campeiros & $0 \%$ \\
\hline Venditti (2009) & São Paulo & Ovinos & $19,3 \%$ \\
\hline Venditti (2009) & São Paulo & Bovinos & $74,1 \%$ \\
\hline Antoniassi (2010) & Rio Grande do Sul & Ovinos & $100 \%$ \\
\hline
\end{tabular}

Fonte: Dados da pesquisa.

Rev. Acad., Ciênc. Agrár. Ambient., Curitiba, v. 9, n. 4, p. 407-413, out./dez. 2011 
coordenação desses esforços ou até mesmo a vontade de instituir uma vigilância epidemiológica ativa. Supõe-se que a pequena presença de casos clínicos esteja relacionada igualmente à falta de conhecimento dos criadores e técnicos sobre essa enfermidade e a uma taxa desconhecida de subnotificação. Por isso, um programa de fiscalização sanitária mais eficiente (na produção, no abate, no transporte e na comercialização) e investimentos estruturais (laboratórios, pessoal técnico, vacinação, pesquisas, rastreabilidade e acompanhamento das questões sanitárias no comércio multilateral e regional) são elementos indispensáveis para a conquista de novos mercados e o fortalecimento do produto nacional naqueles previamente conquistados (VENDITTI, 2009). Igualmente, dever-se-ia conseguir a cooperação do produtor, esclarecendo-o a respeito das vantagens de se ter um rebanho livre do vírus, e a efetiva capacidade organizacional de todos os envolvidos nessa tarefa.

\section{Conclusão}

A LA é uma doença que sabidamente acomete os ruminantes domésticos e silvestres do Brasil. Faltam, no entanto, informações mais precisas sobre a sua epidemiologia e ocorrência no país. Países europeus combatem a doença e tentam restringir ao máximo a circulação viral, desenvolvendo formas preventivas como tentativa de evitar o contágio dos seus rebanhos, utilizando, por exemplo, as vacinações.

Caso não sejam realizados esforços conjuntos de pesquisadores, produtores e governo no intuito de compreender em detalhes tanto a biologia dos vetores quanto a biologia viral do VLA no Brasil, o território brasileiro estará continuamente à mercê das consequências de barreiras sanitárias, além da aceitação de pífios índices produtivos em nossos rebanhos.

\section{Referências}

ABREU, V. L. Prevalência de bovídeos reagentes à prova de imunodifusão para a Língua Azul na região norte do Brasil. 1982. 45 f. Dissertação (Mestrado em Ciências Veterinárias) - Escola de Veterinária, Universidade Federal de Minas Gerais, Belo Horizonte, 1982.
ALVES, F. A. L. et al. Soroprevalência e fatores de risco para língua azul em carneiros das mesorregiões do Sertão e da Borborema, semi-árido do Estado da Paraíba, Brasil. Ciência Rural, v. 39, n. 2, p. 484-489, 2008.

ANTONIASSI, N. A. B. Aspectos clínicos e patológicos da infecção pelo vírus da língua azul em ovinos no Estado do Rio Grande do Sul. 2010. 55 f. Dissertação (Mestrado em Ciências Veterinárias) - Curso de Pós-Graduação em Medicina Veterinária, Universidade Federal do Rio Grande do Sul Porto Alegre, 2010.

ARITA, G. M. et al. Comparison of indirect immunofluorescence with agar gel immunodiffusion for the diagnosis of bluetongue virus infection. Brazilian Journal of Medical and Biological Research, v. 25, n. 5, p. 503-508, 1992.

CASTRO, R. S. et al. Prevalence of antibodies to selected viruses in bovine embryo donors and recipients from Brazil, and its implication in international embryo trade. Tropical Animal Health and Production, v. 24, p. 173176, 1992.

CLAVIJO, A. et al. Isolation of bluetongue virus serotype 12 from an outbreak of the disease in South America. Veterinary Record, v. 151, p. 301-302, 2002.

CORRÊA, T. G. et al. Seasonal allergic dermatitis in sheep in southern Brazil caused by Culicoides insignis (Diptera: Ceratopogonidae). Veterinary Parasitology, v. 145, p. 181185, 2007.

COSTA, J. R. R. Produção e padronização de antígenos para língua azul e prevalência nas mesorregiões sudoeste e sudeste do Estado do Rio Grande do Sul. 2000, 51 f. Dissertação (Mestrado em Medicina Veterinária Preventiva) - Universidade Federal de Minas Gerais Belo Horizonte, 2000.

COSTA, J. R. R. et al. Prevalência de anticorpos contra o vírus da Língua Azul em bovinos e ovinos do Sudoeste e Sudeste do Rio Grande do Sul. Arquivo Brasileiro de Medicina Veterinária e Zootecnia, v. 58, p. 273-275, 2006.

CUNHA, R. G. et al. Anticorpos precipitantes para o Vírus da Língua Azul em soros de bovinos do Estado do Rio de Janeiro. Biológico, v. 48, n. 4, p. 99-103, 1982.

CUNHA, R. G. et al. Anticorpos para o vírus da língua azul em soros de bovinos do Estado de São Paulo e da região Sul do País. Revista Brasileira de Medicina Veterinária, v. 9, p. 121-124, 1987. 
CUNHA, R. G. et al. Incidência de anticorpos para o vírus da Língua Azul em soros de caprinos e ovinos do estado do Rio de Janeiro. Arquivos Fluminense de Medicina Veterinária, v. 3, p. 53-56, 1988.

DUFOUR, B. et al. Global change: impact, management, risk approach and health measures - the case of Europe. OIE Scientific and Technical Review, v. 27, p. 541-550, 2008.

FROTA, M. N. L. et al. Levantamento sorológico do vírus da língua azul em ovinos do Estado do Ceará. Ciência Animal, v. 11, n. 2, p. 84-86, 2001.

GIBBS, E. P. J.; GREINER, E. C. The epidemiology of bluetongue. Comparative Immunology, Microbiology and Infectious Diseases, v. 17, n. 3/4, p. 207-220, 1994.

GOMES, A. C. Contribuições do laboratório de entomologia da Faculdade de Saúde Pública para o conhecimento de endemias brasileiras. Revista de Saúde Pública, v. 21, n. 3, p. 163-166, 1987.

GROOCOCK, C. M.; CAMPBELL, C. H. Isolation of an exotic serotype of bluetongue virus from imported cattle in quarantine. Canadian Journal of Comparative Medicine, v. 46, p. 160-164, 1982.

KIRCHVINK, N. et al. Impact of a natural bluetongue serotype 8 infection on semen quality of Belgian rams in 2007. The Veterinary Journal, v. 182, p. 244-251, 2009.

KONRAD, P. A. et al. Anticorpos contra o vírus da língua azul em bovinos leiteiros de Minas Gerais e associações com problemas reprodutivos. Revista da FZVA, v. 10, n. 1, p. 117-125. 2003.

LOBATO, Z. I. P. et al. Língua azul em ovinos e caprinos na Região Mineira da SUDENE. In: CONGRESSO BRASILEIRO DE BUIATRIA, 1., 2001, Campo Grande. Anais... Campo Grande: Sociedade Brasileira de Buiatria, 2001. p. 165.

MACLACHLAN, N. J. Bluetongue: pathogenesis and duration of viraemia. Veterinaria Italiana, n. 40, p. 462-467, 2004.

MERCOSUL/GMC/RES. Resolução n. 16/05. Requisitos e certificados Zoossanitários para o intercâmbio de animais ovinos entre os estados partes do Mercosul (Revoga RES GMC n. 66/94). 2005. Disponível em: <www.mercosur.int>. Acesso: 20 jan. 2010.
MOTTA, I. O. Anticorpos contra vírus do grupo da língua azul em caprinos e ovinos do sertão de Pernambuco e inferências sobre sua epidemiologia em regiões semi-áridas. 2009. 56 f. Dissertação (Mestrado em Ciências Veterinárias) - Curso de Medicina Veterinária, Universidade Federal de Pernambuco Recife, 2009.

MOREIRA, E. C. et al. Teste de imunodifusão para língua azul em alguns municípios do Brasil. In: ENCONTRO DE PESQUISA DA ESCOLA DE VETERINÁRIA DA UFMG, 9. 1980, Belo Horizonte. Anais... Belo Horizonte: Núcleo de Assessoramento à Pesquisa, 1980. p. 83.

MÜLLER, U. et al. Effects of bluetongue virus infection on sperm quality in bulls: a preliminary report. The Veterinary Journal, v. 186, p. 402-403, 2010.

NOGUEIRA, A. H. C. et al. Detecção de anticorpos contra o Vírus da Língua Azul em ovinos na região de Araçatuba, São Paulo, Brasil. Ciência Animal Brasileira, v. 10, n. 4 p. 1271-1276, 2009.

\section{OFFICE INTERNATIONAL DES EPIZOOTIES - OIE. Manual} of Diagnostic Tests and Vaccines for Terrestrial Animals. 2008. Disponível em: <www.oie.int>. Acesso em: 15 set. 2010 .

PINHEIRO, R. R. et al. Viroses de pequenos ruminantes. Embrapa Caprinos, n. 46, p. 13-17, 2003.

SAEGERMAN, C. et al. The impact of naturally-occurring, trans-placental bluetongue virus serotype-8 infection on reproductive performance in sheep. Veterinary Journal n. 187, p. 72-80, 2010.

SCHWARTZ-CORNIL, I. et al. Bluetongue virus: virology, pathogenesis and immunity. Veterinary Research, v. 39 , n. 5, p. 39-46, 2008.

SILVA, J. et al. Frequência de febre aftosa, língua azul e leucose enzoótica bovina em cabras de Minas Gerais, Brasil. Arquivo Brasileiro de Medicina Veterinária e Zootecnia, v. 40, n. 960, p. 393-403, 1988.

SILVA, M. X. Soroprevalência da língua azul em caprinos e sua associação com indicadores de tecnologia em propriedades do Ceará. 2002. 83 f. Dissertação (Mestrado em Medicina Veterinária Preventiva) - Escola de Veterinária, Universidade Federal de Minas Gerais, Belo Horizonte, 2002. 
TOMICH, R. G. P. Processo saúde-doença de bovinos em rebanhos de assentamentos rurais do município de Corumbá, MS. 2007. 182 f. Tese (Doutorado em Microbiologia), Universidade Federal de Minas Gerais, Belo Horizonte, 2007.

TOMICH, R. G. P. et al. Sorologia para o vírus da língua azul em bovinos de corte, ovinos e veados campeiros no Pantanal sul-mato-grossense. Arquivo Brasileiro de Medicina Veterinária e Zootecnia, v. 61, n. 5, p. 1222-1226, 2009.

VENDITTI, L. L. R. Infecção pelo vírus da língua azul em ovinos e bovinos na região Sudeste do Brasil. 2009. 77 f. Dissertação (Mestrado em Sanidade, Segurança Alimentar e Ambiental no Agronegócio) - Instituto Biológico, São Paulo, 2009.
VELTHUIS, A. G. J. et al. Financial consequences of the Dutch bluetongue serotype 8 epidemics of 2006 and 2007. Preventive Veterinary Medicine, v. 93, p. 294304, 2010.

WALTON, T. E. et al. Epizootiology of bluetongue virus: transmission cycle, vectors and serotypic distribuition in the Americas. Preventive Veterinary Medicine, v. 2, n. 1/4, p. 379-388, 1984.
Recebido: 26/09/2011

Received: 09/26/2011

Aprovado: 15/12/2011

Approved: 12/15/2011 